Хайкин Сергей Романович

кандидат философских наук, советник руководителя Федерального агентства по делам национальностей (ФАДН России), научный руководитель Института социального маркетинга (ИНСОМАР)

\section{ВАРИАНТЫ РЕДИЗАЙНА ПАРТИЙНО-ПОЛИТИЧЕСКОЙ СИСТЕМЫ В РОССИИ: ОПЫТ ЭМПИРИЧЕСКОГО ИССЛЕДОВАНИЯ [1]}

\section{Аннотация:}

Статья посвящена изучению текущего состояния $u$ перспектив переформатирования партийно-политической системы России в интересах развития общества. Изложенные в работе положения выстроены на основании обобщения ре зультатов маситабного социологического исследования, методология которого представляла собой комбинирование кабинетного исследования, фокус-групп, экспертных интервью и закрытых экспертных сессий. Автор анализирует идеологические основы партийно-политической системы России, оценивает ее восприятие избирателями, исследует функциональную эффективность партий как потенциальных выразителей интересов и ценностей макросоциальных групп. Выделен ряд основополагающих условий функционирования и возможной перезагрузки рос сийской партийно-политической системы. Изучены идеологические запросы электората по отношению к политическим партиям. Дана характеристика акторам российской политической системы. Обозначены варианты дизайна партийного пространства - трехпартийный и многопартийный. Проект реализован в 2019 г.

Ключевые слова:

партийно-политическая система, политические партии, Россия, «Единая Россия», КПРФ, ЛДПР, "Справедливая Россия», идеология.

\section{Khaikin Sergey Romanovich}

PhD, Advisor to the Head of the Federal Agency for Nationalities (FADN), Scientific Director, Institute of Social Marketing (INSOMAR)

\section{REDESIGN OPTIONS FOR THE PARTY-POLITICAL SYSTEM IN RUSSIA: THE EXPERIENCE OF EMPIRICAL RESEARCH [1]}

Summary:

The study explores the current state and prospects of reformatting the party-political system of Russia in the interests of the development of society. The provisions set forth in the work are built on the basis of a generalization of the results of a large-scale sociological study, the methodology of which was a combination of desk research, focus groups, expert interviews and closed expert sessions. The author analyzes the ideological foundations of the party-political system of Russia, assesses its perception by voters, explores the functional effectiveness of parties as potential spokesmen for the interests and values of macro-social groups. Several fundamental conditions for the functioning and possible reboot of the Russian party-political system are highlighted. The ideological demands of the electorate in relation to political parties are studied. The actors of Russian political system are described. The variants of the party space design are indicated: three-party and multi-party. The project was implemented in 2019.

Дискуссии о партийной системе в России не теряют актуальности в силу того, что сама система является «живым организмом», реагирующим на социальные изменения. Исследователи неоднократно обращались к теме развития партийно-политической системы России. Соответствующую проблематику в своих работах раскрыли Е.В. Барис [2], Л.Г. Бызов [3], А.В. Гайсина [4], О.В. Гаман-Голутвина [5], А.А. Зиновьев [6], Л.М. Карапетян [7], Л.И. Никовская [8], М.К. Фадеев [9]. Многочисленные комментарии по актуальным вопросам партийного строительства и политической конкуренции дают эксперты-политологи [10] и социологи [11]. При этом сохраняется дефицит работ, посвященных системному рассмотрению и осмыслению функционирования партийно-политической системы в современной России.

Восполнить этот пробел призвано масштабное социологическое исследование, проведенное научным коллективом под руководством С.Р. Хайкина совместно с РГГУ при фринансовой поддержке РФФИ и АНО ЭИСИ в рамках проекта № 19-011-31538 «Редизайн партийно-политической системы как условие развития российского общества». Его целью являлось определение перспективных направлений переформатирования партийно-политической системы России в интересах развития общества.

В рамках своих изысканий участники проекта использовали комплекс взаимосвязанных и взаимодополняющих методов, включавший в себя кабинетное исследование, серию из 10 фокус- 
групп в 5 регионах РФ, 20 экспертных интервью и 2 закрытые экспертные сессии по типу круглых столов и мозговых штурмов.

Кабинетное исследование включило анализ значительно корпуса российских и зарубежных источников (список источников по отчету содержит 151 наименование), часть из которых представлена в данной статье [12]. Анализ вторичной статистической, социологической и исторической информации о партийном строительстве в РФ и развитии политической системы с 1991 г. до настоящего времени позволил исследовать вопросы развития политической системы в Новейшее время в России и странах Европы.

Фокус-групповые дискуссии проводились в пяти субъектах Федерации, которые были отобраны с точки зрения обеспечения структурного разнообразия политической жизни.

- Москва - крупнейший по численности регион с опытом политических протестов.

- Санкт-Петербург: сложная избирательная кампания по выборам главы региона в 2019 г., либеральные настроения.

- Нижегородская область: недавно избранный губернатор с высоким уровнем оценок, позиции «Единой России» выше среднего уровня по РФ.

- Волгоградская область: сложная социально-экономическая ситуация, позиции «Единой России» выше среднего уровня по РФ, высокая доля «периферии» «Единой России».

- Приморский край: сложная избирательная кампания 2018 г., специфическое проблемное поле.

Структура фокус-групп по политическим взглядам формировалась следующим образом:

- обычные избиратели с различными политическими взглядами (3 группы, различный возраст - молодежь, средний возраст, пенсионеры);

- представители «локомотивного» класса - предприниматели, представители высокообразованного слоя населения (2 группы);

- респонденты либеральных взглядов (1 группа);

- консерваторы-патриоты (1 группа);

- представители «периферии», голосующей за «Единую Россию», - избиратели, которые, выбирая «Единую Россию», не исключают для себя возможность голосовать за другие партии (3 группы, различный возраст - молодежь, средний возраст, пенсионеры).

Интервью с федеральными и региональными экспертами проводились в формате беседы в свободной форме по заранее разработанному сценарию. Экспертами выступили ведущие политологи, социологи, экономисты. 10 интервью проведено с федеральными экспертами, 10 с региональными. География экспертных интервью включает Волгоградскую, Иркутскую, Нижегородскую, Оренбургскую, Челябинскую области, Республику Удмуртия, Хабаровский край.

Экспертные сессии по типу круглых столов и мозговых штурмов были проведены в завершение проекта. Цель - обсуждение и интерпретация результатов фокус-групп и экспертных интервью, формирование сценариев развития страны в случае выбора различных вариантов дизайна партийно-политического пространства. В экспертных сессиях приняли участие 35 ученых и практикующих политконсультантов в Москве и 29 специалистов в Санкт-Петербурге. Каждое обсуждение длилось около двух с половиной часов. Результатом стало внесение дополнений и коррективов в предложенные варианты редизайна партийно-политической системы России.

Обобщение результатов исследования позволило сделать следующие выводы.

Современный политический спектр в России сложно укладывается в традиционные оси деления на «правых» и «левых», «либералов» и «консерваторов». Во-первых, идеологическая основа действующих политических партий зачастую содержит противоречивые установки. Во-вторых, избиратели формулируют эклектичные ценностные запросы.

Партийная система воспринимается населением и экспертами как вторичная по отношению к вертикали исполнительной власти. Ключевые задачи партий - легитимизация решений власти, симуляция демократических процедур. Избирательная процедура, по мнению населения, не выполняет функцию представительства интересов народа во власти. Избранные депутаты всех уровней действуют исключительно в личных или узкокорпоративных интересах. Подтверждение тому - текущая законодательная деятельность.

Граждане не видят возможности влиять на ситуацию в стране: общественные организации слабы, партии не заинтересованы в изменениях. Единственный работающий механизм - личное обращение к президенту.

Экспертное мнение, знание и информация из эмпирических источников позволяют декларировать кризис системы представительства в современной России. Можно выделить ряд основополагающих условий функционирования и возможной перезагрузки политической системы. 
1. В современной России доминирует лево-консервативный тренд общественных настроений. Наиболее востребованной стратегией развития страны является «Социальное благополучие». Стратегические ориентиры - качественные и доступные медицина и образование, новая индустриализация как база социального благополучия.

2. Традиционные либеральные ценности - свобода слова и собраний, свобода предпринимательства, свобода передвижения - в общественном мнении являются продуктом эволюции. Они осуществятся «сами собой» по достижении определенного уровня развития. Они не противоречат лево-консервативным идеалам, а дополняют их. Идеи либерализма находят больший отклик среди жителей мегаполисов.

3. В общественном сознании и экспертных мнениях отсутствует единство понимания того, что брать за консервативный идеал общественного устройства - советское прошлое или дореволюционное наследие.

Восприятие основных парламентских партий демонстрирует следующие закономерности (некоторых из них представлены в аналитическом отчете по результатам экспертных интервью и кабинетного исследования 2018 г.).

1. «Единая Россия» остается партией В.В. Путина и российской бюрократии, однако «правильная и системная стратегия партстроительства гарантирует данной структуре перспективы остаться одним из краеугольных камней российской политической системы» [13, с. 13]. «Несомненным преимуществом партии является использование механизмов праймериз, благоприятной внешней и внутриполитической ситуации» [14]. При этом в партии существует кризис ярких образов и «романтики будней», отсутствует платфрорма для эмоционального единения членов.

Мифологемы «Единой России» описываются довольно простыми и в своей простоте эффрективными элементами: «харизматичный Путин», «начальство, которому виднее», «Крым наш», «Россия встала с колен», «мир в Чечне», «стабильность и выплаты бюджетникам вовремя», «борьба с олигархами», «полеты со стерхами и на истребителе» - это чрезвычайно сильные и действенные образы [15].

Поскольку население полностью отождествляет партию с руководством всех уровней, рейтинг партии приобретает дополнительную устойчивость. В благоприятные периоды он подпитывается успехами страны, в неблагоприятные - желанием «теснее сплотиться», продемонстрировать лояльность государственным институтам [16].

2. КПРФ существует в российском политическом пространстве благодаря эксплуатации «советского мифа». Партии довольно удачно удается обеспечить устойчивое функционирование, однако она плохо отвечает условиям современности, недостаточно эволюционирует в сторону социал-демократии, личные карьерные интересы руководства превалируют над потребностями омоложения партии. В перспективе структура может эффективно использовать протестную повестку, связанную с повышением пенсионного возраста.

Основные проблемы партии: расколы и борьба внутрипартийной элиты; неизменное (постоянное) руководство; отсутствие серьезного кадрового омоложения партии; непоследовательность действий партии и идеологической направленности (партия выступает за общество, исключающее эксплуатацию, при этом кандидатом в президенты Российской Федерации в 2018 г. был выдвинут представитель «крупного капитала» П.Н. Грудинин); затруднительно привлечение молодого поколения через интернет и социальные сети; отсутствие яркого лидера - представителя революционного романтизма, популяризация которого в социальных сетях позволит привлечь молодое поколение; склонность к формальной стороне партийной работы.

3. ЛДПР - пример уникального позиционирования на российском «политическом рынке». Это просматривается с точки зрения как социальной базы партии (мужское население российских городов с низким доходом и уровнем образования), так и роли партии как «упаковщика» протестных настроений и лаборатории инноваций в государственном строительстве. Вождистский принцип построения структуры не исключает возможности быстрой перестройки, переформатирования имеющейся повестки и смены руководства. Региональные отделения партии - примеры социальных лифтов для лояльных власти, но не включенных в «Единую Россию» предпринимателей. Партия активно осваивает цифровые технологии, обеспечивает вещание канала «ЛДПР ТВ». ЛДПР отличает привилегия поднимать национальный вопрос и даже включать его в актуальную предвыборную повестку дня [17, с. 14-15].

4. «Справедливая Россия» испытывает трудности с ответом на существующий общественный запрос. Ей не удалось «нащупать» социал-демократическую нишу вне электората КПРФ. Попытки оседлать «протестную повестку» Болотной площади выглядели авантюрно. Исполнительная власть в регионах не воспринимает структуры в качестве «второй партии» власти и успешно отбирает у нее голоса в пользу «Единой России». Бренд партии часто приватизиру- 
ется региональными предпринимателями и оппозиционными политиками [18, с. 15]. Не исключены локальные успехи и избрание ярких политиков по территориальным округам. «Инновационная» идея «Социализма 2.0» не нашла поддержки со стороны избирателей [19].

Если суммировать идеологические запросы современного жителя России, он создает для себя партию с идеологическими рамками либерально-консервативного консенсуса и социал-демократическими ценностями. Все респонденты говорят о необходимости равного доступа к основным благам - медицине, образованию, социальной помощи. Для большинства важно равенство всех перед законом. Наблюдается, что и консервативные, и либеральные ценности характерны для одних и тех же респондентов, одни и те же собеседники говорят и о сильном государстве, и о свободе личности, равенстве всех перед законом, свободе предпринимательства и свободе слова.

Чаще всего упоминается требование сделать основные параметры качества жизни независимыми от уровня доходов. Эта идеологема фрормулируется как «равный доступ ко всем видам ресурсов»: природным ископаемым, государственным финансам, образованию, социальной защите, справедливости. У большинства избирателей создается впечатление, что государство старается освободить себя от значительной части социальных обязательств, тогда как избиратели, наоборот, ждут улучшения качества государства, усиления его социальной функции.

Вторая идеологема, казалось бы, противоречит первой. Условно ее можно назвать «развитие предпринимательства», «свобода зарабатывать».

Третья идеологема - «модернизация и открытость, самостоятельность». Здесь чувствуется, что потенциал мобилизации вокруг «осажденной крепости» заканчивается. Существует потребность в мотивах, которые уже высказывались в статье «Россия сосредотачивается». Вместо идеи противостояния коллективному Западу и неполноценности его ценностного универсума, третирования европейских социальных практик, у части избирателей нарастает чувство, что «Россия есть европейская держава».

Четвертая идеологема - «нравственность». Избирателям хочется создать «партию честных людей», которые вернут моральное измерение в политическую деятельность. Сюда же примыкает борьба с коррупцией. Часть респондентов помещает в свою программу требование об изъятии активов, нажитых нечестным путем, и перенаправлении их на социальные нужды. К этой же совокупности требований относятся открытость, возможность контролировать бюджет и доходы чиновников, разбираться в тонкостях бюджетного процесса. Часть респондентов воспринимает государство как «корпорацию чиновников», которые преследуют собственные интересы, живут сами для себя и вследствие феномена распределенности власти слабо подвержены общественному контролю.

Пятая идеологема - «комфортная городская среда», «сплоченность», социальное государство, «социал-демократия», «партия садоводов». Эти идеи прочитываются как ответ на констатацию общей неустроенности и отсутствия комфорта в современном городском пространстве. Общество быстро фрагментировалось и отчасти связано социальными сетями, но интуитивно ощущает, что в последние десятилетия возник ряд новых практик, связанных с эксплуатацией жилья, взаимопомощью, развитием садоводческих хозяйств, культурными инициативами, деятельностью НКО. Эти новые явления «не замечаются» политиками, в то время как в условиях стагнирующего потребления культивирование ряда социальных технологий вполне может компенсировать недостаток финансовых средств.

Если обобщить пять идей, которые высказываются респондентами, то следует отметить три их качества: привлекательность для большинства, определенную «левизну» и отсутствие «харизмы», энергии, которая побуждала бы вербовать активных сторонников. Общая идея, которая объединяет все перечисленное, - идея суверенитета, эффективной конкуренции в технологической области, адекватного ответа на современные риски и вызовы. Эта тема проговаривается, но иногда недостаточно артикулируется, является общим местом, с которым согласны все.

Все перечисленное важно, но идеологическую ценность все мероприятия, вытекающие из идеологем, приобретают только тогда, когда служат сверхценности - сохранению России как общего социального организма, по отношению к существованию которого все остальные достижения обладают инструментальным характером, хотя и важны для обеспечения «комфорта». Именно опора на идею территориальной целостности позволила «Единой России» достичь впечатляющих электоральных успехов в начале ее истории. По сути, эти же вызовы стоят перед страной и в XXI в., только риски распада относятся не к территории, а к социуму. Пропагандистская кампания в поддержку структуры, объединенной данными идеями, будет выглядеть правдивой и одновременно крайне эмоционально привлекательной. Например, борьба за комфортную среду - это способ вести конкуренцию, часть глобального позиционирования страны. Это позволяет соединить в сознании избирателей «большие» ценности государственного строительства и простые жизненные радости. 
Существующие альтернативы общественно-политического развития определяют возможности реализации двух основных вариантов редизайна партийно-политической системы: трехпартийного и многопартийного.

В трехпартийной системе соперничают центристская, левая и правая партии. «Государственники»-центристы получают 45-50 \% голосов избирателей на федеральных выборах. Их идеология основывается на государственном участии в управлении экономикой, активной внешней политике, отстаивании статуса великой державы, концентрации ресурсов в федеральном центре, формировании государственных резервов и стратегических программ развития.

Левый фланг представлен социал-демократами, чьи идеи разделяют 35-40 \% населения. Их ключевые программные пункты: равенство при распределении общественного богатства, прогрессивное налогообложение, базовый социальный доход, протекционизм на рынке труда, социальная взаимопомощь, гарантированное бесплатное образование и здравоохранение.

Либеральная правая партия занимает 10-15 \% в парламенте. Ее идеи основаны на ценностях частного предпринимательства, личной инициативы, развития территорий, необходимости частной медицины и образования, контроля общества за государственными расходами.

Размежевание по идеологическому признаку позволит создать партийные интеллектуальные центры, занимающиеся не политтехнологиями, а общественной экспертизой и продвижением партийных ценностей. Четкие идеологические ориентиры будут препятствовать появлению авантюристических и популистских идей. Есть возможность повысить критически низкое уважение к парламенту, а значит, и к системе государственной власти РФ в целом. Профессия политика приобретет новое содержание.

К числу угроз можно отнести противодействие имеющихся партийных институтов, сопротивление лоббистских группировок, недовольство депутатского корпуса. Возможно зарождение новых коалиций, построенных по региональному признаку, новых полюсов политических интересов. Более прозрачная политическая система может обнажить недостатки исполнительной власти и запустить процесс ее смены и обновления.

Многопартийная система позволяет представить в институциональном поле весь легальный политический спектр. Таким образом будет предложена альтернатива несанкционированным протестным действиям: острые вопросы будут выведены в политическое поле. Подлинная многопартийность позволит запустить реальный механизм общественной экспертизы законодательных инициатив и стратегий с разных идеологических позиций. Широкий партийный спектр сформирует дополнительный социальный лифт для пассионарной молодежи, которая сейчас не считает политическую сферу привлекательной для карьеры.

Многопартийный вариант несет в себе ряд угроз. Нежелание коммунистов становиться ни левыми радикалами, ни умеренными социал-демократами приведет к появлению дополнительного напряжения на левом фланге. «Украинизация» российской политики - постоянные конфоликты в интернете, драки непосредственно в Государственной думе будут способствовать снижению авторитета парламента. Дефицит финансовых средств для функционирования малых партий превратит их в товары в «политическом супермаркете». Принятие непоследовательных государственных решений как результат разновекторного компромисса уменьшит эффективность государственной политики. Соблазн выбрать из многих простое и привлекательное решение для избирателя - электоральная база безответственного популизма.

Проведенный исследовательский проект убедительно подводит к выводам, согласно которым реформирование российской партийно-политической системы является необходимым условием позитивной социальной динамики. Ряд трудностей и парадоксов развития, пережитые страной кризисы сделали систему политического представительства такой, какой она является сейчас. В трансформированном виде она будет лучше соответствовать актуальным вызовам развития государства.

\section{Ссылки и примечания:}

1. Исследование выполнено научным коллективом под руководством С.Р. Хайкина совместно с РГГУ при финансовой поддержке РФФИ и АНО ЭИСИ в рамках научного проекта № 19-011-31538 «Редизайн партийно-политической системы как условие развития российского общества».

2. Барис Е.В. Особенности эволюции российской партийно-политической системы в постсоветский период и ее современное состояние // Труд и социальные отношения. 2009. № 10. С. 132-137.

3. Бызов Л.Г. Политические и мировоззренческие ценности россиян и трансформация партийно-политической системы России // Мониторинг общественного мнения: экономические и социальные перемены. 2008. № 3 (87). С. 4-16.

4. Гайсина А.В. Политические партии и партийная система России: к вопросу о классификации // Вестник Забайкальского государственного университета. 2019. Т. 25, № 2. С. 63-71. https://doi.org/10.21209/2227-9245-2019-25-2-63-71.

5. Гаман-Голутвина О.В. Особенности эволюции системы партийно-политического представительства в России // Социология власти. 2004. № 3. С. 89-103.

6. Зиновьев А.А. Идеология партии будущего. М., 2018. 238 с. 
7. Карапетян Л.М. Конституция и партийно-политическая избирательная система в России // Конституционное и муниципальное право. 2006. № 2. С. 9-19.

8. Никовская Л.И. Гражданский активизм и публичная политика в России: состояние и вызовы // Государство и граждане в электронной среде. 2017. № 1. С. 144-158.

9. Фадеев М.К. Теоретико-методологические проблемы изучения современной партийно-политической системы России // Известия высших учебных заведений. Северо-Кавказский регион. Серия: Общественные науки. 2011. № 4 (164). C. 58-62.

10. Винокуров А. Жертвы политических депрессий [Электронный ресурс] // Коммерсантъ. 2019. № 221. 30 нояб. URL: https://www.kommersant.ru/doc/4178529 (дата обращения: 23.01.2020) ; Вятчанин Н. Госдума-2021 будет формироваться по другим правилам [Электронный ресурc] // Парламентская газета. 2017. 12 окт. URL: https://www.pnp.ru/politics/gosduma-2021-budet-formirovatsya-po-drugim-pravilam.html (дата обращения: 23.01.2020); Галлямов А. Будущее российских партий [Электронный ресурс] // ПОЛИТ.PУ. 2018. 2 апр. URL: http://polit.ru/article/2018/04/02/parties/ (дата обращения: 23.01.2020) ; Григорий Казанков: Российская партийная система разваливается на глазах [Электронный ресурс] // Выбор народа. 2018. 28 июня. URL: http://2018.vybor-naroda.org/stovyborah/114481-grigoriy-kazankov-rossiyskayapartiynaya-sistema-razvalivaetsya-na-glazah.html (дата обращения: 23.01.2020) ; Дальнейшее развитие России невозможно без изменения политической системы [Электронный ресурс] // Актуальные комментарии. 2017. 2 июня. URL: http://actualcomment.ru/1111-1706021227.html (дата обращения: 23.01.2020); Доклад ЦЭПР. КПРФ на развилке: чтобы победить - нужно меняться [Электронный ресурс] // ЦЭПР. 2017. 25 дек. URL: http://cepr.su/2017/12/25/kprf/ (дата обращения: 23.01.2020) ; Максимов Г. Эксперты: ЛДПР и «Справедливая Россия» скоро исчезнут [Электронный ресурс] // ФедералПресс. 2018. 22 янв. URL: http://fedpress.ru/article/1941875 (дата обращения: 23.01.2020) ; Миронов Н. Российская оппозиция: ждать ли перемен [Электронный ресурс] // ПОЛИТ.PУ. 2018. 29 марта. URL: http://polit.ru/article/2018/03/29/politics/ (дата обращения: 23.01.2020) ; Мухаметшина Е. Осенние выборы станут ключевыми для российской партийной системы [Электронный ресурс] // Ведомости. 2018. 12 июля. URL: https://www.vedomosti.ru/politics/articles/2018/07/13/775370-osennie-vibori-partiinoi-sistemi (дата обращения: 23.01.2020) ; Партийная система в России: надежда на изменения или продолжение застоя? [Электронный ресурс] // Выбор народа. 2018. 15 июня. URL: http://2018.vybor-naroda.org/stovyborah/113604-partiynaya-sistema-v-rossii-nadezhda-na-izmeneniya-ili-prodolzheniezastoya.html (дата обращения: 23.01.2020).

11. Белановский С., Дмитриев М., Никольская А. Признаки изменения общественных настроений и их возможные последствия. М., 2018. 55 с.

12. 40 пунктов программы греческой СИРИЗА [Электронный ресурс] // Вести Экономика. 2015. 30 янв. URL: https://www.vestifinance.ru/articles/52631 (дата обращения: 23.01.2020) ; Забелин С.А., Власова К.Ю. Левые радикалы Греции: прорыв во власть // Выборы и избирательные кампании в Европе (2014-2015) : доклад Института Европы № 320 / отв. ред. В.Я. Швейцер. М., 2015. С. 58-68 ; Ларионова М.В. Дискурсивная стратегия испанской партии «Подемос»: политика как борьба за смыслы // Известия Саратовского университета. Новая серия. Серия: Филология. Журналистика. 2017. Т. 17, № 4. С. 389-394. https://doi.org/10.18500/1817-7115-2017-17-4-389-394 ; Маслова Е.А. Евроскептицизм и популизм в Италии: пример «Движения пяти звезд» // Контуры глобальных трансформаций: политика, экономика, право. 2017. Т. 10, № 1. C. 141-157. https://doi.org/10.23932/2542-0240-2017-10-1-141-157 ; Нарочницкая Е.А. Непредвиденные итоги выборов 2017 г. во Франции: общее и особенное, закономерное и случайное // Выборы во Франции 2017 г.: итоги и перспективы : доклад Института Европы № 347 / отв. ред. В.Я. Швейцер. М., 2017. С. 11-20 ; Платонова Д. Битва глобалистов и патриотов. [Электронный ресурс] // Взгляд. Деловая газета. 2017. 21 апр. URL: https://vz.ru/opinions/2017/4/21/867290.html (дата обращения: 23.01.2020) ; Последние ультрас: «Пари Сен-Жермен» и расправа с футбольными фанатами во Франции [Электронный ресурс] // PROSM. 2018. 1 марта. URL: http://prosm.club/2018/03/01/poslednie-ultras-pari-sen-zhermen-irasprava-s-futbolnymi-fanatami-vo-francii (дата обращения: 23.01.2020) ; Рахманов А.С. Северная модель правого радикализма (на примере праворадикальных партий и движений Норвегии) // Вопросы истории и культуры северных стран и территорий. 2016. № 3 (35). С. 76-91; Степанов Г.В. «Альтернатива для Германии» - альтернатива для разочаровавшихся избирателей? // Консервативные, социальные и либеральные тенденции в партийно-политическом развитии Германии и России: история и современность : материалы международного научного семинара. Череповец, 2017. С. 229235 ; Филина Н.В. Партия «Альтернатива для Германии» как феномен партийной системы ФРГ [Электронный ресурс] // Электронный научный журнал. 2016. № 8 (11). C. 148-151. URL: http://co2b.ru/docs/enj.2016.08.pdf (дата обращения: 23.01.2020) ; Хенкин С.М. Меняющийся облик партийной системы Испании // Выборы и избирательные кампании в Европе (2014-2015). С. 47-58 ; Экономическая программа оппозиционной партии «Подемос» [Электронный ресурс]. 2015. URL: https://4ru.es/ru/all-news/menu-politics/2551-ekonomicheskaya-programma-oppozitsionnoj-partii-podemos (дата обращения: 23.01.2020) ; Шибкова М.О. Идеологический и стратегический евроскептицизм в политической жизни Евросоюза // Сравнительная политика. 2016. Т. 7, № 4 (25). С. 13-24. https://doi.org/10.18611/2221-3279-2016-7-4(25)-13-24 ; Eiendomsskatt [Электронный ресурc]. URL: https://www.frp.no/tema/skatter-og-avgifter/eiendomsskatt (дата обращения: 23.01.2020); EU-politik [Электронный ресурс] // PIRATPARTIET. URL: https://www.piratpartiet.se/eu-politik/ (дата обращения: 23.01.2020) ; Les 144 engagements présidentiels [Электронный ресурc]. URL: https://rassemblementnational.fr/le-projet-de-marine-le-pen/ (дата обращения: 23.01.2020) ; Programma movimento 5 stelle [Электронный ресуpc]. URL: https://www.movimento5stelle.it/ (дата обращения: 23.01.2020).

13. Партийно-политическая система в России: состояние и перспективы развития [Электронный ресурс] : аналитический отчет по результатам экспертных интервью и кабинетного исследования. М., 2018. 23 c. URL: http://www.prisp.ru/images/pdf/insomar_analitik2.pdf (дата обращения: 23.01.2020).

14. Там же.

15. Там же.

16. Там же.

17. Там же. С. $14-15$

18. Там же. С. 15.

19. Там же.

\section{References:}

Baris, EV 2009, 'Features of the Evolution of the Russian Party-Political System in the Post-Soviet Period and Its Current State', Trud i social'nye otnoshenija, no. 10, pp. 132-137, (in Russian).

Belanovsky, S, Dmitriev, M \& Nikolskaya, A 2018, Signs of a Change in Public Sentiment and Their Possible Consequences, Moscow, 55 p., (in Russian). 
Byzov, LG 2008, 'Political and Worldview Values of Russians and the Transformation of the Party-Political System of Russia', Monitoring obshhestvennogo mnenija: ekonomicheskie i social'nye peremeny, no. 3 (87), pp. 4-16, (in Russian).

Fadeev, MK 2011, 'Theoretical and Methodological Problems of Studying the Modern Party-Political System of Russia', Izvestija vysshih uchebnyh zavedenij. Severo-Kavkazskij region. Serija: Obshhestvennye nauki, no. 4 (164), pp. 58-62, (in Russian).

'Further Development of Russia is Impossible Without Changing the Political System' 2017, Aktual'nye kommentarii, viewed 23 January 2020, <http://actualcomment.ru/1111-1706021227.html>, (in Russian).

Filina, NV 2016, 'Party "Alternative for Germany" as a Phenomenon of the Party System of Germany', Elektronnyj nauchnyj zhurnal, no. 8 (11), viewed 23 January 2020, pp. 148-151, <http://co2b.ru/docs/enj.2016.08.pdf>, (in Russian).

Gallyamov, A 2018, 'The Future of Russian Parties', POLIT.RU, viewed 23 January 2020, <http://polit.ru/article/2018/04/02/parties/>, (in Russian).

Gaman-Golutvina, OV 2004, 'Features of the Evolution of the System of Party-Political Representation in Russia', Sociologija vlasti, no. 3, pp. 89-103, (in Russian).

Gaysina, AV 2019, 'Political Parties and party System of Russia: On the Issue of Classification', Vestnik Zabajkal'skogo gosudarstvennogo universiteta, vol. 25, no. 2, pp. 63-71, https://doi.org/10.21209/2227-9245-2019-25-2-63-71, (in Russian).

Karapetyan, LM 2006, 'Constitution and Party-Political System in Russia', Konstitucionnoe i municipal'noe pravo, no. 2, pp. 9-19, (in Russian).

Kazankov, G 2018, 'The Russian Party System is Falling Apart Before Our Eyes', Vybor naroda, viewed 23 January 2020, <http://2018.vybor-naroda.org/stovyborah/114481-grigoriy-kazankov-rossiyskaya-partiynaya-sistema-razvalivaetsya-na-

glazah.html>, (in Russian).

Khenkin, SM 2015, 'The Changing Face of the Party System of Spain', Elections and Election Campaigns in Europe (20142015), in VYa Schweizer (ed.), Elections and Election Campaigns in Europe (2014-2015): Institute of Europe Report No. 320, Moscow, pp. 47-58, (in Russian).

Larionova, MV 2017, 'Discourse Strategy of the Spanish Political Party Podemos: Politics as a Struggle for Meanings', Izvestia Saratovskogo universiteta. Novaya seria. Seria: Filologia. Zhurnalistika, vol. 17, no. 4, pp. 389-394, https://doi.org/10.18500/1817-7115-2017-17-4-389-394, (in Russian).

Maksimov, G 2018, 'Experts: LDPR and Just Russia Will Soon Disappear', FederalPress, viewed 23 January 2020, $<$ http://fedpress.ru/article/1941875>, (in Russian).

Maslova, EA 2017, 'Eurosceptism and Populism in Italy: The Example of "Five Stars" Movement', Kontury global'nyh transformacij: politika, ekonomika, pravo, vol. 10, no. 1, pp. 141-157, https://doi.org/10.23932/2542-0240-2017-10-1-141-157, (in Russian).

Mironov, N 2018, 'Russian Opposition: Should We Wait for Change', POLIT.RU, viewed 23 January 2020, <http://polit.ru/article/2018/03/29/politics/>, (in Russian).

Mukhametshina, E 2018, 'Autumn Elections will Become Key for the Russian party system', Vedomosti, viewed 23 January 2020, <https://www.vedomosti.ru/politics/articles/2018/07/13/775370-osennie-vibori-partiinoi-sistemi>, (in Russian).

Narochnitskaya, EA 2017, 'Unforeseen Results of the 2017 Elections in France: General and Special, Regular and Random', in VYa Schweizer (ed.), Elections in France 2017: Results and Prospects: Report of the Institute of Europe No. 347, Moscow, pp. 11-20, (in Russian).

Nikovskaya, LI 2017, 'Civic Activism and Public Policy in Russia: State and Challenges', Gosudarstvo i grazhdane $v$ elektronnoj srede, no. 1, pp. 144-158, (in Russian).

Party-Political System in Russia: State and Development Prospects: Analytical Report on the Results of Expert Interviews and Desk Research, 2018, Moscow, viewed 23 January 2020, <http://www.prisp.ru/images/pdf/insomar_analitik2.pdf>, (in Russian).

Platonova, D 2017, 'Battle of Globalists and Patriots', Vzgljad. Delovaja gazeta, viewed 23 January 2020, <https://vz.ru/opinions/2017/4/21/867290.html>, (in Russian).

Rakhmanov, AS 2016, 'Northern Model of Right-Wing Radicalism (On the Example of the Right-Wing Radical Parties and Movements of Norway)', Voprosy istorii i kul'tury severnyh stran i territorij, no. 3 (35), pp. 76-91, (in Russian).

Shibkova, MO 2016, 'Ideological and Strategic Euroscepticism in EU Politics', Sravnitel'naja politika, vol. 7, no. 4 (25), pp. 13-24, https://doi.org/10.18611/2221-3279-2016-7-4(25)-13-24, (in Russian).

Stepanov, GV 2017, 'Alternative for Germany" - an Alternative for Frustrated Voters?', Conservative, Social and Liberal Trends in the Political Party Development of Germany and Russia: History and Modernity: Materials of an International Scientific Seminar, Cherepovets, pp. 229-235, (in Russian).

Vinokurov, A 2019, 'Victims of Political Depressions', Kommersant, no. 221, viewed 23 January 2020, <https://www.kommersant.ru/doc/4178529>, (in Russian).

Vyatchanin, N 2017, 'State Duma-2021 Will Be Formed According to Other Rules', Parlamentskaja gazeta, viewed 23 January 2020, <https://www.pnp.ru/politics/gosduma-2021-budet-formirovatsya-po-drugim-pravilam.html>, (in Russian).

Zabelin, SA \& Vlasova, KYu 2015, 'Left-Wing Radicals of Greece: a Breakthrough in Power', in VYa Schweizer (ed.), Elections and Election Campaigns in Europe (2014-2015): Institute of Europe Report No. 320, Moscow, pp. 58-68, (in Russian).

Zinoviev, AA 2018, The Ideology of the Party of the Future, Moscow, 238 p., (in Russian).

Редактор: Тальчук Калерия Сергеевна Переводчик: Ездина София Александровна 